\title{
Colorectal carcinoma masked by systemic inflammatory response syndrome: A case report
}

\author{
HONGYUN WEI ${ }^{1}$, WAQAS CHOUDHARY ${ }^{1}$, RONG HE ${ }^{1}$, CHUNHUI OUYANG ${ }^{1}$, \\ ZONGYONG CHENG ${ }^{1}$, DELIANG LIU ${ }^{1}$, FANGGEN LU ${ }^{1}$ and XIAOWEI LIU ${ }^{2}$ \\ ${ }^{1}$ Department of Gastroenterology, The Second Xiangya Hospital, Central South University, Changsha, Hunan 410011; \\ ${ }^{2}$ Department of Gastroenterology, Xiangya Hospital, Central South University, Changsha, Hunan 410008, P.R. China
}

Received May 25, 2016; Accepted June 21, 2017

DOI: $10.3892 / 01.2017 .6820$

\begin{abstract}
The present study described the case of a 68-year-old woman who presented to the Second Xiangya Hospital of Central South University (Changsha, China) with progressive abdominal pain, distention and diarrhea. These symptoms were diagnosed as the initial manifestations of systemic inflammatory response syndrome associated with colorectal carcinoma (CRC). The presentation appeared as a common emergency medical case, which was eventually recognized as a CRC masked by this emergency symptom. This case highlights the fact that a correct diagnosis can be made by looking through the outward appearance to perceive the essence of the condition. Therefore, vigilant surveillance is of utmost importance in order to expedite prompt recognition and rapid management of this presentation of CRC.
\end{abstract}

\section{Introduction}

Colorectal carcinoma (CRC) is one of the most prevalent types of cancer in humans globally $(1,2)$. In the United States, a report revealed that $\mathrm{CRC}$ incidence rates were lowest among Asian/Pacific residents, and highest in Alaska natives. CRC-induced mortality decreased by $34 \%$ in individuals aged $\geq 50$ between 2000 and 2014, but increased by $13 \%$ among those aged $<50$ (3). Patients with CRC present with multiple

Correspondence to: Professor Xiaowei Liu, Department of Gastroenterology, Xiangya Hospital, Central South University, 87 Xiangya Road, Changsha, Hunan 410008, P.R. China

E-mail: liuxw@csu.edu.cn

Professor Fanggen Lu, Department of Gastroenterology, The Second Xiangya Hospital, Central South University, 139 Middle Renmin Road, Changsha, Hunan 410011, P.R. China

E-mail: lufanggenyao@163.com

Abbreviations: SIRS, systemic inflammatory response syndrome; $\mathrm{CRC}$, colorectal carcinoma; CEA, carcinoembryonic antigen

Key words: colorectal carcinoma, systemic inflammatory response syndrome symptoms that are commonly associated with the disease, including abdominal pain, fatigue (4), obstruction, perforation and bleeding (5). The medical literature associated with emergencies in patients with CRC is dominated by reports of obstruction, perforation, overt bleeding (6), and systemic inflammatory response subsequent to curative resection of CRC (7). To the best of our knowledge, systemic inflammatory response syndrome (SIRS) has not been previously reported as the primary indication of CRC or other diseases. SIRS is the result of occult infection or sterile inflammation (8), and is characterized by multi-organ failure and increased mortality $(9,10)$. A prompt diagnosis of underlying disease is necessary for early intervention and appropriate treatment. SIRS is associated with poor prognosis in patients with CRC $(11,12)$. The present study described a patient with CRC that presented with SIRS as the early clinical indication without a history of chronic diseases.

\section{Case report}

A 68-year-old woman presented to the Emergency Department of Changsha Central Hospital (Changsha, China) with worsening symptoms of abdominal pain late in the evening of June 1,2015 . These symptoms were accompanied by an urge to defecate 4 times/day, severe abdominal distention and vomiting, and a low-grade fever with a body temperature not exceeding $37.9^{\circ} \mathrm{C}$ (normal range, $36-37^{\circ} \mathrm{C}$ ). Abdominal radiographs were performed to ascertain the cause of the symptoms (Fig. 1A). The patient was diagnosed with acute gastroenteritis and admitted to the hospital for the administration of $80 \mathrm{mg}$ phloroglucinol intramuscularly. However, the symptoms were found to be exacerbated even after treatment. Bloody diarrhea was reported four times a day, and the urine volume decreased to a maximum of $100 \mathrm{ml}$ in a $24 \mathrm{~h}$ period (normal range, $1,000-2,000 \mathrm{ml}$ in a $24 \mathrm{~h}$ period). The patient was consequently referred to the Department of Gastroenterology of the Second Xiangya Hospital (Central South University, Changsha, China) for further diagnosis and treatment on June 2, 2015.

The patient had a history of long-term consistent abdominal pain that was relieved following defecation. The patient had also suffered from asthma for $>10$ years. There was no previous history of weight loss, cigarette smoking or renal disease. A physical examination revealed shock, with limb 


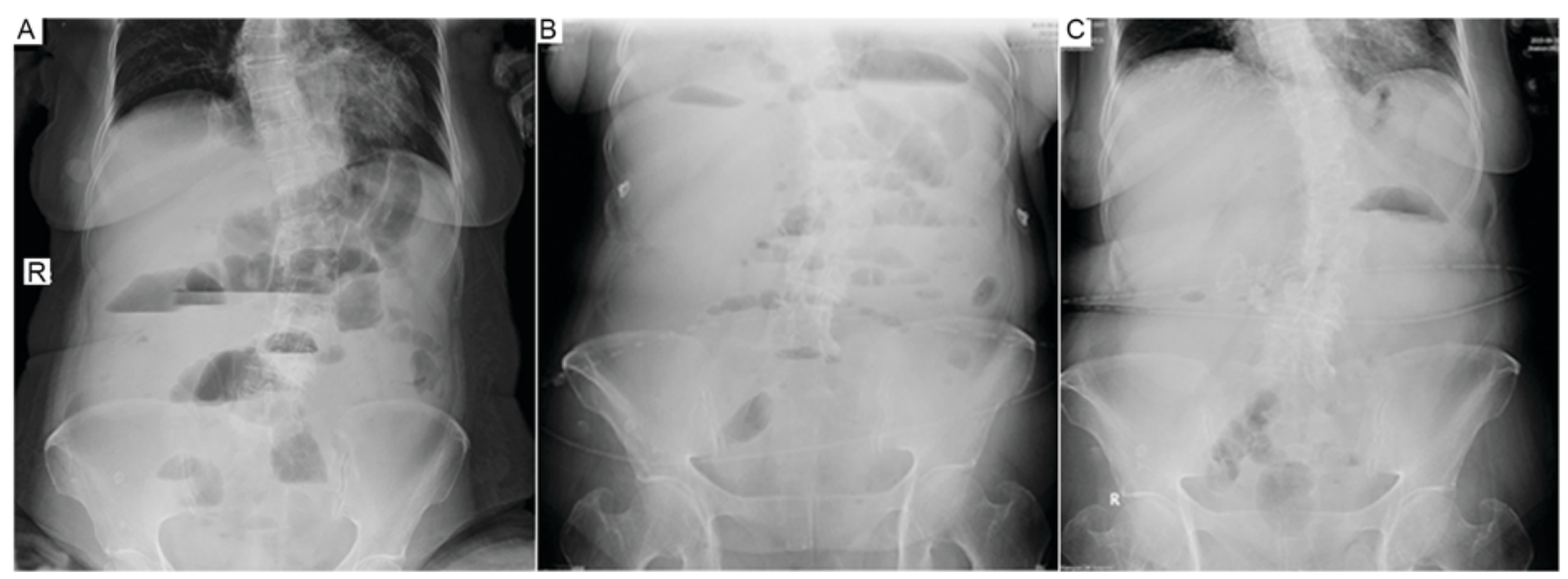

Figure 1. Upright abdominal X-ray films. (A) Abundant free air in the intestinal lumina on day 1. (B) Free air in the intestinal lumina on day 2. (C) Upright abdominal X-ray film after 1 month revealing the existence of free air in the intestinal lumina.

clamminess, a body temperature of $37^{\circ} \mathrm{C}$, blood pressure of 92/50 $\mathrm{mmHg}$ (normal range, 90-120/60-80 mmHg), tachycardia (145 beats/min; normal range, $60-100$ beats $/ \mathrm{min}$ ) and tachypnea ( 22 breaths/min; normal range, $12-20$ breaths/min). There were diminished breath sounds at each lung base. Upon abdominal examination, peritonitis with a firm consistency was found, with rebound tenderness and hypoactive bowel sounds at a frequency of 3-4 times/min. Laboratory tests revealed a white blood cell count (WBC) of $1.526 \times 10^{10} / 1$ (normal range, $3.5-9.5 \times 10^{9} / 1$ ) with $92.8 \%$ neutrophils (normal range, $40-75 \%$ ), a serum hemoglobin level of $135 \mathrm{~g} / 1$ (normal range, $130-175 \mathrm{~g} / \mathrm{l}$ ), a platelet count of $1.62 \times 10^{11} / 1$ (normal range, 1.25-3.50 $\left.\times 10^{11} / 1\right)$, an elevated erythrocyte sedimentation rate $(\mathrm{ESR})$ that ranged from $20-118 \mathrm{~mm} / \mathrm{h}$ (normal range, 0-20 mm/h), a procalcitonin (PCT) level of $25.06 \mathrm{~g} / 1$ (normal range, $<0.05 \mathrm{ng} / \mathrm{ml}$ ) and a C-reactive protein level of $351 \mathrm{mg} / \mathrm{l}$ (normal range, $0-8 \mathrm{mg} / \mathrm{l}$ ). Hepato-renal function tests demonstrated increased levels of blood urea nitrogen (BUN) at $46.69 \mathrm{mmol} / 1$ (normal range, $2.9-7.14 \mathrm{mmol} / \mathrm{l}$ ), creatinine at $367.2 \mu \mathrm{mol} / 1$ (normal range, $40-133 \mu \mathrm{mol} / \mathrm{l}$ ) and alanine aminotransferase (ALT) at $107.9 \mu / 1$ (normal range, 9-50 $\mu / 1$ ), and a raised aspartate aminotransferase (AST) level of 136.9 U/1 (normal range, 15-40 U/l). The BNP level reached $8,392 \mathrm{pg} / \mathrm{ml}$ (normal range, $0-900 \mathrm{pg} / \mathrm{ml}$ ). Arterial blood gas and electrolyte related laboratory data showed acidosis with a $\mathrm{pH}$ of 7.281 (normal range, 7.35-7.45), partial pressure ( $\mathrm{Pa}) \mathrm{CO}_{2}$ of $55.6 \mathrm{mmHg}$ (normal range, 32-45 mmHg), $\mathrm{PaO}_{2}$ of $55.6 \mathrm{mmHg}$ (normal range, $83-108 \mathrm{mmHg}$ ), a bicarbonate level of $13.5 \mathrm{mmol} / \mathrm{l}$ (normal range, 21-28 mmol/l) and electrolyte disturbance with a low blood calcium level of $1.41 \mathrm{mmol} / 1$ (normal range, 2.03-2.54 mmol/l). Coagulation function tests showed increased fibrinogen degradation products at $44.89 \mu \mathrm{g} / \mathrm{ml}$ (normal range, $0-5 \mu \mathrm{g} / \mathrm{ml}$ ), an extended prothrombin time of $17.9 \mathrm{sec}$ (normal range, 11-13 sec), a prolonged activated partial thromboplastin time of $66.1 \mathrm{sec}$ (normal range, 25-33 sec) and a fibrinogen concentration of $70.6 \mathrm{mg} / \mathrm{dl}$ (normal range, 200-400 mg/dl). The concentration of carcinoembryonic antigen (CEA) was $87.720 \mathrm{ng} / \mathrm{ml}$ (normal range, $<5 \mathrm{ng} / \mathrm{ml}$ ). No positive results were found for serum antinuclear antibodies, extractable nuclear antigen or any other immunological biomarkers.
An electrocardiogram (ECG) indicated supraventricular tachycardia. Chest X-rays showed exudative lesions at each lung base. An abdominal X-ray disclosed the existence of incomplete intestinal obstruction (Fig. 1B). Scans of the thorax and abdomen were made prior to and following treatment of SIRS (Fig. 2). As shown in Fig. 2A-C, lung infection and intestinal obstruction with dilatation were observed on computed tomography scans prior to treatment.

According to a consensus conference in 1992, the defining characteristic of SIRS is the presence of any two diagnostic criteria among the following: Abnormal temperature $\left(>38^{\circ} \mathrm{C}\right.$ or $\left.<36^{\circ} \mathrm{C}\right)$, heart rate $(>90$ beats $/ \mathrm{min})$, respiratory rate $(>20$ breaths $/ \mathrm{min})$ and $\mathrm{WBC}$ count $\left(>12 \times 10^{9} / 1\right.$ or $\left.<4 \times 10^{9} / 1\right)(13-15)$. In the present case, the heart rate was 145 beats/min and the respiratory rate was 22 breaths/min. In consideration of acute multi-organ function disturbances such as kidney, heart and lung dysfunction, the patient was diagnosed with SIRS. The patient was immediately administered $1 \mathrm{~g}$ meropenem intravenously every $8 \mathrm{~h}$ along with nutrition support therapy. After almost 1 month of treatment, the symptoms were observed to improve. The WBC count improved to $8.15 \times 10^{9} / 1$ with $64 \%$ neutrophils, PCT decreased to $0.08 \mathrm{~g} / 1$ and hepato-renal function tests showed normal levels of BUN, ALT and AST. Furthermore, a sinus rhythm was also detected upon ECG. Most importantly, the patient exhibited no trace of infection or multi-organ disturbance.

However, unexpectedly, the hemoglobin level was reduced to $95 \mathrm{~g} / 1$ (normal range, 130-175 g/1), and the stool occult blood test remained positive. A secondary abdominal X-ray revealed trapped gas located mainly in the lower right quadrant of the abdomen (Fig. 1C).

Considering the presence of anemia, bloody stool and intestinal dilatation, a colonoscopy was performed to aid the diagnosis. A laterally spreading tumor with uneven nodules was detected in the descending colon. Narrow band imaging staining disclosed the presence of type IIIA and type VA pits based on pit structure and superficial microvessel features, and identified using Kudo's pit pattern classification (16), which were indicative of a carcinogenic lesion. This lesion was thus endoscopically diagnosed as CRC (Fig. 3A and B). Biopsy of the tumor areas showed atypical tissues suggestive 

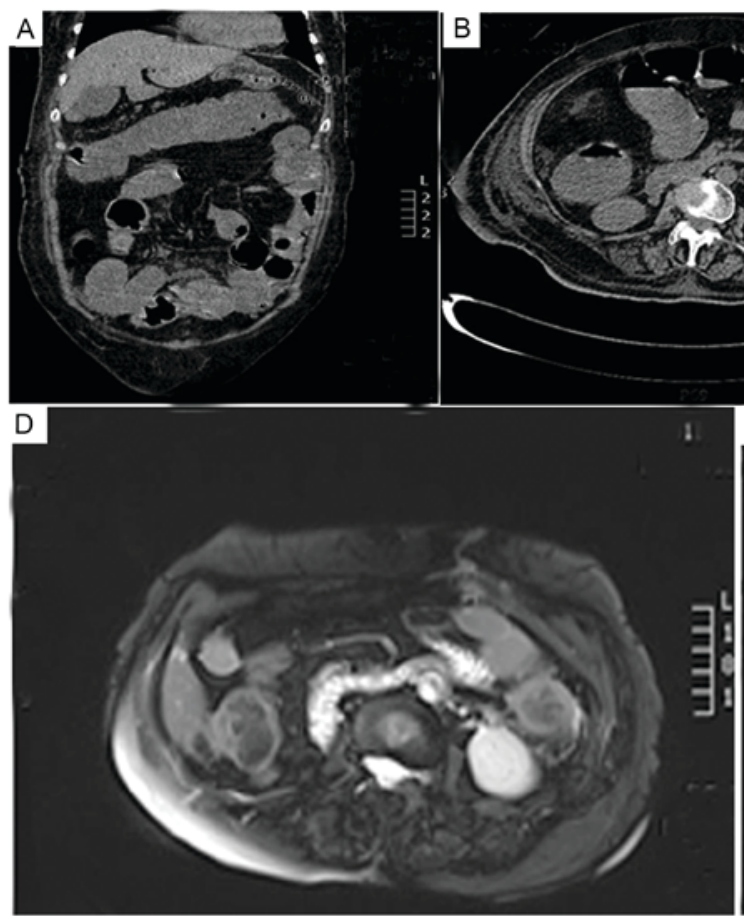

Figure 2. Abdominal imaging examination prior to and following the treatment of systemic inflammatory response syndrome. (A) Sagittal and (B) coronal planes of a CT scan revealing that the intestinal lumina were filled with air. (C) CT scan showing infection in the lungs. (D and E) At 1 month post-surgery, magnetic resonance imaging examination revealed no recurrence. CT, computed tomography.
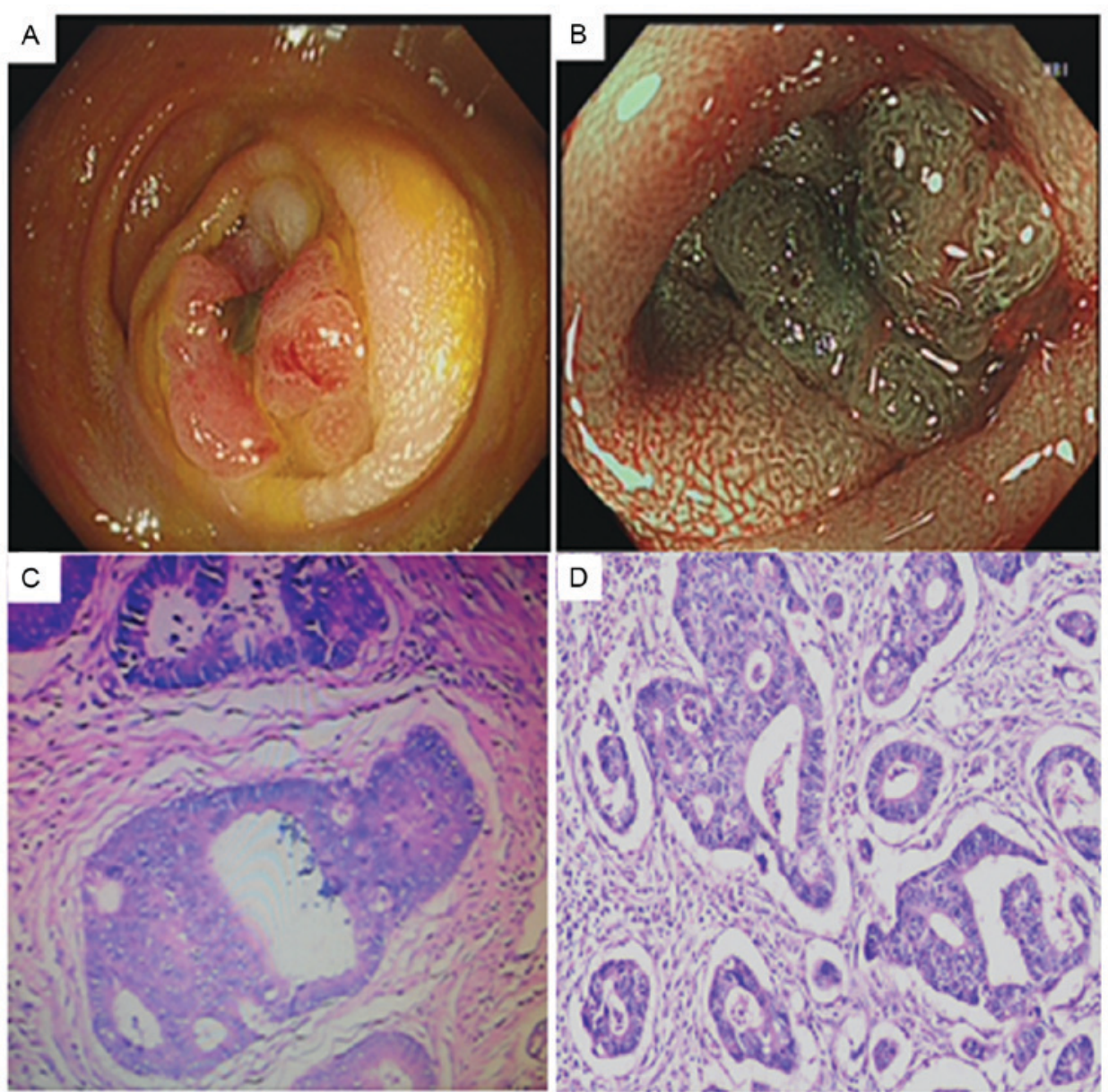

Figure 3. Colonoscopy and histological findings. (A) Colonoscopy images showing a laterally spreading tumor, $40 \mathrm{~mm}$ in diameter, in the descending colon (B) Narrow band imaging revealing distorted and branched blood vessels. Histological findings in (C) pre-operative biopsy (H\&E staining; magnification, $\mathrm{x} 200$ ) or (D) post-operative sample (H\&E staining; magnification, $\mathrm{x} 100)$. H\&E, hematoxylin and eosin. 
of adenocarcinoma, as shown in Fig. 3C. Thus, the patient was advised to undergo surgical removal of $12 \mathrm{~cm}$ of the colon descendens. The final histopathological diagnosis was of a moderately differentiated colorectal adenocarcinoma without metastasis (Fig. 3D).

Subsequent to the surgery, the patient refused to undergo chemotherapy. The patient's quality of life was mostly normal, with no evidence of any complications. During the 1-month follow-up after surgery, no recurrence or metastasis of the CRC were observed upon magnetic resonance imaging (Fig. 2D and E). As of April 1, 2016, 8 months post-surgery, no fever, abdominal pain or other symptoms were present, and the blood tests, including blood cell levels, the serum levels of BUN, ALT, AST and CEA, and the ESR have been normal. A telephone follow-up will be performed every 6 months until the time of patient mortality, and a telephone follow-up on 25th June, 2017 showed the patient has been feeling well so far with no signs of recurrence and metastasis were tracked following CT examination.

Written informed patient consent was obtained for the publication of the present study.

\section{Discussion}

Recent studies have reported that systemic inflammatory response is a predictor of prognosis in patients with CRC $(7,11,17,18)$. Certain published studies have also reported the association between emergency presentation and poor cancer-specific survival times following curative resection (6). However, systemic inflammation has not been previously reported as the primary manifestation. The association between SIRS and clinical symptoms of CRC is thus rare and this rarity could render this symptom as a warning sign for its diagnosis.

SIRS is a rapidly progressive syndrome that causes significant morbidity and has a high rate of mortality if not treated promptly, and it is usually secondary to other clinical manifestations, including carcinoma and severe infection (19). Due to SIRS patients presenting as an emergency case at first admission, the primary cause tends to be ignored, leading to a missed diagnosis of the primary disease (20).

Potential mechanisms involved in the occurrence of SIRS in CRC patients may be associated with the fact that the gut is a habitat pool for 100 trillion microbiota, a number of which have been reported to be associated with the development of CRC (21-23). Gut microbiota can influence the normal development and function of the mucosal immune system, such as modification of T-cell repertoires and T-helper cell cytokine profiles (24-26). Intestinal epithelial cells maintain a moderate immune response against, or tolerance for, non-pathogenic bacteria via Toll-like receptors (TLRs), which recognize particular molecular motifs of the pathogens (27). Activation of TLRs may lead to the activation of nuclear factor- $\kappa \mathrm{B}$ and mitogen-activated protein kinase pathways, which lead to the development of pro-inflammatory cytokines, such as tumor necrosis factor- $\alpha$ and interleukin-6 (28). Consequently, a cascade reaction is triggered by inflammatory cytokines, which can lead to the development of SIRS with multi-organ dysfunction involving the lungs, heart, kidney and liver.
SIRS is characterized by acute systemic inflammation. However, SIRS could not explain the long-term abdominal pain in the present case. Furthermore, the characteristic symptoms of bloody stool, anemia and persistent incomplete intestinal obstruction warrant more attention. In the current case, a diagnosis of CRC in the early stages of the disease had significant implications on the treatment choices and prognosis of the patient.

Thus, the present study describes an emergency case of SIRS as a primary symptom of CRC, which highlights the importance of analyzing obscure manifestations carefully upon emergency presentation in order to obtain a satisfactory outcome.

\section{Acknowledgements}

The authors would like to thank Miss Lei Shi from the Department of Pathology, Second Xiangya Hospital of Central South University, for providing pathological support.

\section{References}

1. Siegel RL, Miller KD and Jemal A: Cancer Statistics, 2017. CA Cancer J Clin 67: 7-30, 2017.

2. Ferlay J, Soerjomataram I, Dikshit R, Eser S, Mathers C, Rebelo M, Parkin DM, Forman D and Bray F: Cancer incidence and mortality worldwide: Sources, methods and major patterns in GLOBOCAN 2012. Int J Cancer 136: E359-E386, 2015.

3. Siegel RL, Miller KD, Fedewa SA, Ahnen DJ, Meester RGS, Barzi A and Jemal A: Colorectal cancer statistics, 2017. CA Cancer J Clin 67: 177-193, 2017.

4. Müller F, Tuinman MA, Janse M, Almansa J, Sprangers MAG, Smink A, Ranchor AV, Fleer J and Hagedoorn M: Clinically distinct trajectories of fatigue and their longitudinal relationship with the disturbance of personal goals following a cancer diagnosis. Br J Health Psychol, Jun 21, 2017 (Epub ahead of print).

5. Baer C, Menon R, Bastawrous S and Bastawrous A: Emergency presentations of colorectal cancer. Surg Clin North Am 97: 529-545, 2017.

6. McArdle CS and Hole DJ: Emergency presentation of colorectal cancer is associated with poor 5-year survival. Br J Surg 91: 605-609, 2004.

7. McMillan DC, Canna K and McArdle CS: Systemic inflammatory response predicts survival following curative resection of colorectal cancer. Br J Surg 90: 215-219, 2003.

8. Hoque R, Farooq A and Mehal WZ: Sterile inflammation in the liver and pancreas. J Gastroenterol Hepatol 28 (Suppl 1): S61-S67, 2013.

9. Beal AL and Cerra FB: Multiple organ failure syndrome in the 1990s. Systemic inflammatory response and organ dysfunction. JAMA 271: 226-233, 1994.

10. Scott HF, Deakyne SJ, Woods JM and Bajaj L: The prevalence and diagnostic utility of systemic inflammatory response syndrome vital signs in a pediatric emergency department. Acad Emerg Med 22: 381-389, 2015.

11. Carruthers R, Tho LM, Brown J, Kakumanu S, McCartney E and McDonald AC: Systemic inflammatory response is a predictor of outcome in patients undergoing preoperative chemoradiation for locally advanced rectal cancer. Colorectal Dis 14: e701-e707, 2012.

12. McSorley ST, Black DH, Horgan PG and McMillan DC: The relationship between tumour stage, systemic inflammation, body composition and survival in patients with colorectal cancer. Clin Nutr, May 19, 2017 (Epub ahead of print).

13. Bone RC, Balk RA, Cerra FB, Dellinger RP, Fein AM, Knaus WA, Schein RM and Sibbald WJ: Definitions for sepsis and organ failure and guidelines for the use of innovative therapies in sepsis. The ACCP/SCCM consensus conference committee. American college of chest physicians/society of critical care medicine. Chest 101: 1644-1655, 1992.

14. Landis RC: 20 Years on: Is it time to redefine the systemic inflammatory response to cardiothoracic surgery? J Extra Corpor Technol 47: 5-9, 2015. 
15. Castillo-Lara RA, Soria-Ruiz M and Martínez-Carrera O Definitions for sepsis and organ failure. JAMA 270: 939, 1993.

16. Kudo S, Tamura S, Nakajima T, Yamano H, Kusaka H and Watanabe H: Diagnosis of colorectal tumorous lesions by magnifying endoscopy. Gastrointest Endosc 44: 8-14, 1996.

17. Fujita T: Preoperative but not postoperative systemic inflammatory response correlates with survival in colorectal cancer (Br J Surg 2007; 94: 1028-1032). Br J Surg 94: 1439-1440, 2007.

18. Crozier JE, Leitch EF, McKee RF, Anderson JH, Horgan PG and McMillan DC: Relationship between emergency presentation, systemic inflammatory response, and cancer-specific survival in patients undergoing potentially curative surgery for colon cancer. Am J Surg 197: 544-549, 2009.

19. Vincent JL, Opal SM, Marshall JC and Tracey KJ: Sepsis definitions: Time for change. Lancet 381: 774-775, 2013.

20. Comstedt P, Storgaard M and Lassen AT: The systemic inflammatory response syndrome (SIRS) in acutely hospitalised medical patients: A cohort study. Scand J Trauma Resusc Emerg Med 17: 67, 2009.

21. Cuevas-Ramos G, Petit CR, Marcq I, Boury M, Oswald E and Nougayrède JP: Escherichia coli induces DNA damage in vivo and triggers genomic instability in mammalian cells. Proc Natl Acad Sci USA 107: 11537-11542, 2010.
22. Becker S, Oelschlaeger TA, Wullaert A, Vlantis K, Pasparakis M, Wehkamp J, Stange EF and Gersemann M: Bacteria regulate intestinal epithelial cell differentiation factors both in vitro and in vivo. PLoS One 8: e55620, 2013.

23. Gupta A, Madani R and Mukhtar H: Streptococcus bovis endocarditis, a silent sign for colonic tumour. Colorectal Dis 12: 164-171, 2010.

24. Mazmanian SK, Liu CH, Tzianabos AO and Kasper DL: An immunomodulatory molecule of symbiotic bacteria directs maturation of the host immune system. Cell 122: 107-118, 2005.

25. Rakoff-Nahoum S, Paglino J, Eslami-Varzaneh F, Edberg S and Medzhitov R: Recognition of commensal microflora by toll-like receptors is required for intestinal homeostasis. Cell 118: 229-241, 2004.

26. Gagnière J, Raisch J, Veziant J, Barnich N, Bonnet R, Buc E, Bringer MA, Pezet D and Bonnet M: Gut microbiota imbalance and colorectal cancer. World J Gastroenterol 22: 501-518, 2016.

27. Cario E: Bacterial interactions with cells of the intestinal mucosa: Toll-like receptors and NOD2. Gut 54: 1182-1193, 2005.

28. Karin M and Greten FR: NF-kappaB: Linking inflammation and immunity to cancer development and progression. Nat Rev Immunol 5: 749-759, 2005. 